\title{
Formulation, Evaluation and Mathematical Modelling of Clopidogrel Bisulphate \& Aspirin Immediate Release Bilayer Tablets
}

\author{
Abdul Althaf S*, Sailaja PB and Ashwin Kumar M \\ Division of Pharmacy, Sri Venkatswara University, Tirupati, Andhra Pradesh, India
}

\begin{abstract}
The use of a fixed-dose combination (Clopidogrel bisulphate and Aspirin) tablet instead of the individual administration of the two compounds is expected to be more convenient to patients (and thus to improve compliance) by limiting the number of tablets they need to take. Therefore, to improve patient compliance and to decrease the incidence of adverse effects and side effects, Clopidogrel bisulphate and Aspirin are together formulated as an immediate release bilayer tablet. This study is intended to produce an immediate release bilayer tablets using solid dispersion technique. The prepared tablets were evaluated and subjected to dissolution studies.
\end{abstract}

Keywords: Drug delivery system; Formulation of drug; Evaluation

\section{Aim of Study}

Aim of the present study is to formulate a bilayer tablet of Clopidogrel bisulphate and Aspirin of strength $75 \mathrm{mg}$ for once-aday dosing indicated for prophylaxis of athero-thrombotic events. Evaluation and optimization of process parameters as well as finished dosage form also form part of this work.

The objectives of this study are to formulate an immediate-release composition which releases Clopidogrel bisulphate and Aspirin when exposed to gastrointestinal milieu thus facilitating a reduction in frequency of drug administration. And also it develops physicochemically stable drug delivery system. And to improve the solubility of Clopidogrel bisulphate using Solid dispersion technique and in turn improves the bioavailability of Clopidogrel bisulphate. The developed an immediate-release dosage form should have comparable in vitro dissolution profile as compared to marketed product.

\section{Materials}

The API, polymers, other excipients, reagents and equipments used for the development of formulation are given in tables 1-3.

\section{Materials used in bilayer tablet formulation}

Clopidogrelbisulphate, Aspirin, Microcrystallinecellulose(PH-102), PEG-4000, Povidone (K-30), CrosPovidone, Super disintegrant, Sodium starch glycollate, Super disintegrant, Croscarmellose sodium, Super disintegrant, Colloidal silicon sioxide, Glidant, Sodium stearyl fumarate, Supra and Colorant.

\section{Reagents used for analysis}

Hydrochloric acid (AR grade), Potassium chloride (AR grade), Methanol (ARgrade) and Potassium bromide (Aldrich, USA).

\section{Equipment}

Tablet compression machine, Dissolution apparatus-Lab India DS-14000 (Auto sampler), UV-Visible spectrophotometer-Schimadzu 1601, Disintegration apparatus-Electrolab (ED-2AL), Rapid dryerRetsch (TG-100), Loss on drying apparatus-Mettler Toledo (HB 43), Hardness tester, Monsanto tester, Density apparatus- Electrolab (ETD1020), Mechanical shaker-Skan, Roche friabilator USP-Electrolab (EF-1W), Vernier calliper- Mitutoyo (absolute digimatic), Digital pH
meter-Lab India, Digital weighing balance-Mettler Toledo (AB 204-S), FT-IR Spectrophotometer-Bruker Alpha-T equipped with OPUS 6.0 software [1-3].

\section{Preformulation Studies of Clopidogrel Bisulphate and Aspirin}

The use of preformulation parameters maximizes the chances in formulating an acceptable, safe, efficacious and stable product and at same time provides the basis for optimization of the drug product quality. The formal preformulation study starts at the point after biological screening when a decision is made for further development of the compound in clinical trials before embarking on a formal program. The preformulation scientist must consider the following, available Pharmacokinetic data, anticipated dose, supply situation and development schedule, nature of the information the formulator should have or would like to have. The above considerations will offer some guidelines in deciding the types and the urgency of the studies that need the attention. The studies undertaken in this study are as follows:-

Organoleptic properties, the results are presented in table no1.1,1.2. Solubility, micromeritical properties, bulk and tapped density, compressibility index (C.I) and hausner ratio (H.R), angle of repose, analytical method development of Clopidogrel bisulphate and Aspirin immediate release bilayer tablet [4-8].

\section{Analysis of Reference Product}

Reference product was analysed to evaluate its drug release profile so that the formulation being developed can be compared. Further, this will facilitate calculation of the dissimilarity $\left(f_{1}\right)$ and similarity $\left(f_{2}\right)$ dissolution factor. Analysis of the innovator's product was carried out

${ }^{*}$ Corresponding author: Abdul Althaf S, Division of Pharmacy, Sri Venkatswara University, Tirupati, Andhra Pradesh, India, E-mail: abdul.althafi@gmail.com

Received November 06, 2012; Accepted November 19, 2012; Published November 25, 2012

Citation: Abdul Althaf S, Sailaja PB, Ashwin Kumar M (2012) Formulation, Evaluation and Mathematical Modelling of Clopidogrel Bisulphate \& Aspirin Immediate Release Bilayer Tablets. Pharmaceut Anal Acta 3: 194 doi:10.4172/2153-2435.1000194

Copyright: ( 2012 Abdul Althaf S, et al. This is an open-access article distributed under the terms of the Creative Commons Attribution License, which permits unrestricted use, distribution, and reproduction in any medium, provided the original author and source are credited. 
Citation: Abdul Althaf S, Sailaja PB, Ashwin Kumar M (2012) Formulation, Evaluation and Mathematical Modelling of Clopidogrel Bisulphate \& Aspirin Immediate Release Bilayer Tablets. Pharmaceut Anal Acta 3: 194. doi:10.4172/2153-2435.1000194

Page 2 of 11

for various physical parameters and in vitro dissolution profile. Parameters used for evaluation of reference product are description, thickness, hardness, friability, weight variation, in vitro dissolution studies, assay [9].

\section{Compatibility Studies of CPS and ASA with Formulation Excipients}

The study to evaluate compatibility of drug with other excipients under experimental conditions is an important prerequisite before actual formulation is initiated in order to confirm that the drug does not react with the excipients and affect the shelf stability of product. IR spectroscopy study was conducted to identify compatibility between drug and the excipients. Compatibility was studied by comparing the functional groups of CPS and ASA as such and in the prepared formulations [10].

\section{Methodology}

\section{Formulation of Clopidogrel bisulphate and Aspirin immediate-release bilayer tablets}

The aim of the study is to formulate immediate release bilayer tablets of Clopidogrel bisulphate and Aspirin using Solid dispersion technique for the solubility enhancement of Clopidogrel bisulphate. Different disintegrants were selected for this study following literature survey [11-14]. They can be categorized as:

\section{Superdisintegrants}

Sodium starch glycollate, Crospovidone, Croscarmellose sodium.

\section{Process development}

Since Clopidogrel bisulphate is a Class-II drug, its solubility is very low (i.e $0.0099 \mathrm{mg} / \mathrm{ml}$ ). Therefore, "A Solid dispersion technique- Fusion method" is employed to enhance its solubility.

Method: The drug Clopidogrel bisulphate and the carrier PEG-4000 were taken in different ratios by weight. The water soluble carrier i.e., PEG4000 was melted and the drug was finely dispersed into it. The melted mixture was then solidified rapidly in an ice-bath under vigorous stirring. The final solid mass is crushed, pulverized and sieved. This solid dispersion was used for the evaluation of solubility enhancement. The process for the formulation of Clopidogrel bisulphate immediate release layer was developed in a systematic way. Trials were taken by selection of suitable ratio of solid dispersing agent PEG-4000 in which the drug showed greater solubility and its solubility was determined accordingly.

According to the Higuichi-connor's solubility measurement technique, the absorbances were read against the blank using UV-Visible spectroscopy for the different ratios of solid dispersions and their concentrations were calculated accordingly from the regression equation $\mathrm{Y}=\mathrm{mx}+\mathrm{c}$. Where, $\mathrm{Y}=$ absorbance; $\mathrm{m}=$ slope; $\mathrm{x}=$ concentration or solubility of $\mathrm{drug}(\mathrm{mcg} / \mathrm{ml}) ; \mathrm{c}=$ intercept.

\section{Preparation of Bi- Layer Tablet of Cps and ASA}

Formulation of immediate release layer of CPS: The dose of CPS conventional tablets is $75 \mathrm{mg}$. Therefore a loading dose of $75 \mathrm{mg}$ is incorporated in the immediate release layer of the tablet. The following formulae are developed [15-22] (Tables 1 and 2).

\begin{tabular}{|c|c|c|c|c|c|c|c|}
\hline Ingredients (mg) & $C_{1}$ & $\mathrm{C}_{2}$ & $\mathrm{C}_{3}$ & $\mathrm{C}_{4}$ & $\mathrm{C}_{5}$ & $\mathrm{C}_{6}$ & $\mathrm{C}_{7}$ \\
\hline Clopidogrel Bisulphate & 98.0 & 98.0 & 98.0 & 98.0 & 98.0 & 98.0 & 98.0 \\
\hline PEG-4000 & 98.0 & 98.0 & 98.0 & 98.0 & 98.0 & 98.0 & 98.0 \\
\hline Avicel $\mathrm{PH}-102$ & 48.625 & 38.625 & 38.625 & 38.625 & 33.625 & 33.625 & 33.625 \\
\hline Sodium starch glycolate & - & 10 & - & - & 15.0 & - & - \\
\hline Crospovidone & - & - & 10 & - & - & 15.0 & - \\
\hline Croscarmellose sodium & - & - & & 10 & - & - & 15.0 \\
\hline Aerosil & 2.5 & 2.5 & 2.5 & 2.5 & 2.5 & 2.5 & 2.5 \\
\hline Sodium stearyl fumarate & 1.875 & 1.875 & 1.875 & 1.875 & 1.875 & 1.875 & 1.875 \\
\hline Colorant & 1.0 & 1.0 & 1.0 & 1.0 & 1.0 & 1.0 & 1.0 \\
\hline Total & 250 & 250 & 250 & 250 & 250 & 250 & 250 \\
\hline
\end{tabular}

Table 1: Composition of immediate release layer of Clopidogrel bisulphate

\begin{tabular}{|c|c|c|c|c|c|c|c|}
\hline Ingredients (mg) & $A_{1}$ & $A_{2}$ & $A_{3}$ & $\mathrm{~A}_{4}$ & $A_{5}$ & $A_{6}$ & $A_{7}$ \\
\hline Aspirin & 75.0 & 75.0 & 75.0 & 75.0 & 75.0 & 75.0 & 75.0 \\
\hline Avicel pH-102 & 69.0 & 63.0 & 63.0 & 63.0 & 60.0 & 60.0 & 60.0 \\
\hline PVP K-30 & 4.5 & 4.5 & 4.5 & 4.5 & 4.5 & 4.5 & 4.5 \\
\hline Sodium starch glycollate & - & 6.0 & - & - & 9.0 & - & - \\
\hline Crospovidone & - & - & 6.0 & - & - & 9.0 & - \\
\hline Croscarmellose sodium & - & - & - & 6.0 & - & - & 9.0 \\
\hline Sodium stearyl fumarate & 1.5 & 1.5 & 1.5 & 1.5 & 1.5 & 1.5 & 1.5 \\
\hline Total & 150 & 150 & 150 & 150 & 150 & 150 & 150 \\
\hline
\end{tabular}

Table 2: Composition of ASA immediate release layer 
Citation: Abdul Althaf S, Sailaja PB, Ashwin Kumar M (2012) Formulation, Evaluation and Mathematical Modelling of Clopidogrel Bisulphate \& Aspirin Immediate Release Bilayer Tablets. Pharmaceut Anal Acta 3: 194. doi:10.4172/2153-2435.1000194

Page 3 of 11

\section{Preparation of Bilayer Formulation}

\section{Formulation of Clopidogrel bisulphate immediate release layer using direct compression}

Clopidogrel bisulphate solid dispersion and other additives were mixed well by geometric dilution and were passed through sieve no. 30 . To the above portion of the mixture, $1 \%$ of the colloidal silicon dioxide was added separately for the glidant action. Finally, $0.75 \%$ of the sodium stearyl fumarate was added for lubrication.

\section{Formulation of Aspirin immediate release layer using dry granulation}

Weigh all the materials and pass through sieve no. 30 except lubricant. Now mix the above ingredients for 15 min by geometric dilution method. Form Slugs by passing the above mixture through a roller compactor. Break the Slugs in multi- mill, pass through sieve no.30. Pass lubricant, glidant through sieve no. 30 and add to the above granules/mixture. Mix the above blend for $3 \mathrm{~min}$.

\section{Compression}

Finally bilayer tablets were compressed as one layer only for Clopidogrel bisulphate $\left(\mathrm{C}_{1}, \mathrm{C}_{2}, \mathrm{C}_{3}, \mathrm{C}_{4}, \mathrm{C}_{5}, \mathrm{C}_{6}, \mathrm{C}_{7}\right)$ and second layer for Acetyl salicylic acid $\left(A_{1}, A_{2}, A_{3}, A_{4}, A_{5}, A_{6}, A_{7}\right)$ using $11.5 \mathrm{~mm}$ round concave punch in 12 station multi tooling tablet compression machine (Rimek, India) [6]. The tablet was compressed as a bilayer tablet using both Clopidogrel bisulphate and Acetyl Salicylic Acid granules. In this, Clopidogrel bisulphate granules were introduced first into the die cavity and slight pre-compression was made so that layer was uniformly distributed and after that Acetyl Salicylic Acid granules were added and final compression was made [23-27].

\section{Parameters for Evaluation of Designed Formulation}

\section{Pre-compression parameters, post-compression parameters}

Evaluation of compressed tablets: Description, Thickness, Hardness, Friability, Weight variation, Estimation of drug content, In vitro dissolution studies(Calculation of dissimilarity $\left(f_{1}\right)$ and similarity $\left(f_{2}\right)$ factor, Mathematical modeling of in vitro dissolution) and Short term stability studies as per ICH guidelines (for 60 days): Pre-compression parameters.

\section{In vitro dissolution studies}

Following procedure was finalized and employed throughout the study to determine the in vitro dissolution rate for all the formulations (Table 3).

\begin{tabular}{|l|r|}
\hline Dissolution medium & $0.1 \mathrm{~N} \mathrm{HCl} \mathrm{buffer-1} \mathrm{hr}$ \\
\hline Dissolution medium volume & $900 \mathrm{ml}$ \\
\hline Apparatus & USP Type-II, Paddle \\
\hline Speed & $50 \mathrm{rpm}$ \\
\hline Temperature & $37^{\circ} \mathrm{C} \pm 5^{\circ} \mathrm{C}$ \\
\hline Sampling time interval & $5,10,20,30,45$ and $60 \mathrm{~min}$. \\
\hline
\end{tabular}

Table 3: Dissolution parameters

Procedure: Six tablets of each formulation were randomly chosen and weighed. One tablet was transferred into each dissolution vessel containing $900 \mathrm{ml}, 0.1 \mathrm{~N} \mathrm{HCl}$ buffer. After completion of one hour, dissolution was halted and samples were collected. The amount of drug released was determined by analyzing the aliquots removed at regular intervals by UV spectrophotometric method (Tables 4 and 5).

\begin{tabular}{|c|c|c|}
\hline Instrument & \multicolumn{2}{|c|}{ SCHIMADZU-1601 UV Spectrophotometer } \\
\hline Wavelength & \multicolumn{2}{|c|}{$\begin{array}{l}254 \mathrm{~nm} \text { for Clopidogrel Bisulphate } \\
216 \mathrm{~nm} \text { for Aspirin }\end{array}$} \\
\hline Blank solution & \multicolumn{2}{|l|}{$0.1 \mathrm{~N} \mathrm{HCl}$ buffer } \\
\hline Standard solution & \multicolumn{2}{|c|}{$40 \mathrm{ppm}$ solution of Clopidogrel Bisulphate and Aspirin in $0.1 \mathrm{~N} \mathrm{HCl}$ buffer. } \\
\hline Replicates of sample & \multicolumn{2}{|l|}{2} \\
\hline \multicolumn{3}{|c|}{ Table 4: UV parameters. } \\
\hline Drug & Time in min & Amount dissolved \\
\hline Clopidogrel Bisulphate & 30 & NLT $80 \%$ \\
\hline Aspirin & 30 & NLT $80 \%$ \\
\hline
\end{tabular}

Table 5: USP limit for dissolution test -2 .

\section{Drug release models}

Drug release mechanisms and kinetics are the two important characteristics of a drug delivery system in describing drug dissolution profile. To describe the kinetics of the drug release from matrix tablet, mathematical models such as zero-order, first order, Higuchi, Hixson-Crowell and Korsmeyer-Peppas models were used. The criterion for selecting the most appropriate model was chosen on the basis of the goodness of fit test. The zero-order kinetics (equation 1.0) describes the systems in which the drug release rate is independent of its concentration. The first order kinetics (equation 1.1) describes the systems in which the drug release rate is concentration dependent. Higuchi (equation 1.2) described the release of drug from an insoluble matrix as square root of time dependent process. The Higuchi square root model also gives the drug release from a planar surface of an insoluble heterogeneous matrix 
Citation: Abdul Althaf S, Sailaja PB, Ashwin Kumar M (2012) Formulation, Evaluation and Mathematical Modelling of Clopidogrel Bisulphate \& Aspirin Immediate Release Bilayer Tablets. Pharmaceut Anal Acta 3: 194. doi:10.4172/2153-2435.1000194

Page 4 of 11

by diffusion through the intragranular openings created by porosity of the matrix tablet. The Hixson-Crowell cube root law (equation 1.3) describes the drug release from systems in which there is a change in the surface area and the diameter of particle present in tablet. In case of Korsmeyer-Peppas model, the drug release from such devices having constant geometry will be observed till the polymer chains rearrange to equilibrium state. Korsmeyer-Peppas model (equation 1.4) describes the fraction released $Q_{t} / Q_{\infty}$ as power function of time $t$ for short time period.

$$
\begin{aligned}
& \mathrm{Q}_{\mathrm{t}}=\mathrm{K}_{\mathrm{o}} \mathrm{t} \\
& \mathrm{Q}_{\mathrm{t}}=\mathrm{Q}_{\mathrm{o}}\left(1-\mathrm{e}^{-\mathrm{k}}{ }_{1} \mathrm{t}\right) \\
& \mathrm{Q}_{\mathrm{t}}=\mathrm{K}_{\mathrm{H}} \sqrt{\mathrm{t}} \\
& 3 \sqrt{ } \mathrm{Q}_{\mathrm{o}}-3 \sqrt{ } \mathrm{Q}_{\mathrm{t}}=\mathrm{K}_{\mathrm{HC}} \mathrm{t} \\
& \mathrm{Q}_{\mathrm{t}} / \mathrm{Q}_{\infty}=\mathrm{K}_{\mathrm{k}} \mathrm{t}^{\mathrm{n}}
\end{aligned}
$$

$Q_{t}$ - is the amount of drug release in time $t ; Q_{o}$ - is the initial amount of the drug

$\mathrm{F}$ - is the fraction of drug release in time $\mathrm{t} ; \mathrm{n}$ - exponent value, and $\mathrm{K}_{\mathrm{o}}, \mathrm{K}_{1}, \mathrm{~K}_{\mathrm{H}}, \mathrm{K}_{\mathrm{HC}}$ and $\mathrm{K}_{\mathrm{k}}$ are release rate constants for zero-order, first-order, Higuchi, Hixson-Crowell and Korsmeyer-Peppas model rate equations respectively [9].

\section{Stability studies}

Stability of a drug has been defined as the ability of a particular formulation, in a specific container, to remain within its physical, chemical, therapeutic and toxicological specifications. The purpose of stability testing is to provide evidence on how the quality of a drug substance or drug product varies with time under the influence of a variety of environmental factors such as temperature, humidity and light, and enables recommended storage conditions, retest periods and shelf lives to be established [10].

\begin{tabular}{|c|c|c|c|}
\hline S.NO. & Experiment & Property & Observation \\
\hline 1 & Organoleptic Properties & $\begin{array}{c}\text { Colour } \\
\text { Odour } \\
\text { Taste } \\
\text { Appearance }\end{array}$ & $\begin{array}{c}\text { White Powder } \\
\text { Odorless } \\
\text { Bitter } \\
\text { Crystalline Powder }\end{array}$ \\
\hline 2 & Solution Properties & Solubility & $3 \mathrm{mg} / \mathrm{ml}$ in water \\
\hline 3 & Melting Point & - & $156^{\circ} \mathrm{C}-161^{\circ} \mathrm{C}$ \\
\hline 4 & Micromeritical Properties & $\begin{array}{c}\text { Bulk density } \\
\text { Tapped density } \\
\text { Compressibility index } \\
\text { Hausner ratio } \\
\text { Angle of repose }\end{array}$ & $\begin{array}{c}0.658 \mathrm{~g} / \mathrm{ml} \\
0.781 \mathrm{~g} / \mathrm{ml} \\
15.789 \% \\
1.188 \\
23.070^{\circ}\end{array}$ \\
\hline
\end{tabular}

\section{Preformulation study of Clopidogrel Bisulphate (Table 6)}

\begin{tabular}{|l|l|l|l|}
\hline S.No. & Experiment & Property & Observation \\
\hline 1 & Organoleptic Properties & $\begin{array}{l}\text { Colour } \\
\text { Odour } \\
\text { Taste } \\
\text { Appearance }\end{array}$ & $\begin{array}{l}\text { White Powder } \\
\text { Odorless } \\
\text { Tasteless } \\
\text { Amorphous Powder }\end{array}$ \\
\hline 2 & Solution properties & Solubility & $\begin{array}{l}\text { Practically insoluble in water at neutral } \mathrm{pH}, \text { but freely soluble at } \mathrm{pH} 1 \text {; freely soluble in methanol, sparingly } \\
\text { soluble in methylene chloride, and practically insoluble in ethyl ether }\end{array}$ \\
\hline 3 & Melting Point & - & $176.8^{\circ} \mathrm{C}$ \\
\hline 4 & Micromeritical properties & $\begin{array}{l}\text { Bulk density } \\
\text { Tapped density } \\
\text { Compressibility index } \\
\text { Hausner ratio } \\
\text { Angle of repose }\end{array}$ & $\begin{array}{l}0.676 \mathrm{~g} / \mathrm{ml} \\
12.78 \%\end{array}$ \\
\hline & & 1.148 \\
$24.623^{\circ}$
\end{tabular}

Table 6: Observed Properties of active pharmaceutical ingredient, Clopidogrel bisulphate.

\section{Preformulation study of Aspirin (Table 7)}

Table 7: Observed properties of active pharmaceutical ingredient, Aspirin.

The micromeritical studies on pure drug were carried out and the results indicated that the drugs (CPS and ASP) possess excellent flow properties.

\section{Compatibility Studies of Clopidogrel Bisulphate and Aspirin with Formulation Excipients}

The study to evaluate compatibility of drug and other excipients under experimental conditions is an important prerequisite before actual formulation is initiated in order to confirm that the drug does not react with the excipients and affect the shelf stability of product.

\section{Physical observation (visual)}

The API and the excipients are mixed in a fixed dose combination and are visually inspected for any discolouration after a specified period of 
Citation: Abdul Althaf S, Sailaja PB, Ashwin Kumar M (2012) Formulation, Evaluation and Mathematical Modelling of Clopidogrel Bisulphate \& Aspirin Immediate Release Bilayer Tablets. Pharmaceut Anal Acta 3: 194. doi:10.4172/2153-2435.1000194

Page 5 of 11

time to check the compatibility of the drug with various excipients. If there is no discolouration in the physical mixture, then it can be concluded that there is compatibility between drug and the excipients. No discoloration was found in the physical mixture containing Clopidogrel bisulphate and the excipients as well as Aspirin and the excipients. Therefore, it can be concluded that the given list of excipients can be used in the formulation.

\section{Chemical analysis by FTIR spectrophotometer}

FTIR analysis is a type of qualitative analysis which gives us an idea about the Compatibility by comparing the functional groups of drugs as such and in the prepared formulations (Figure 1).
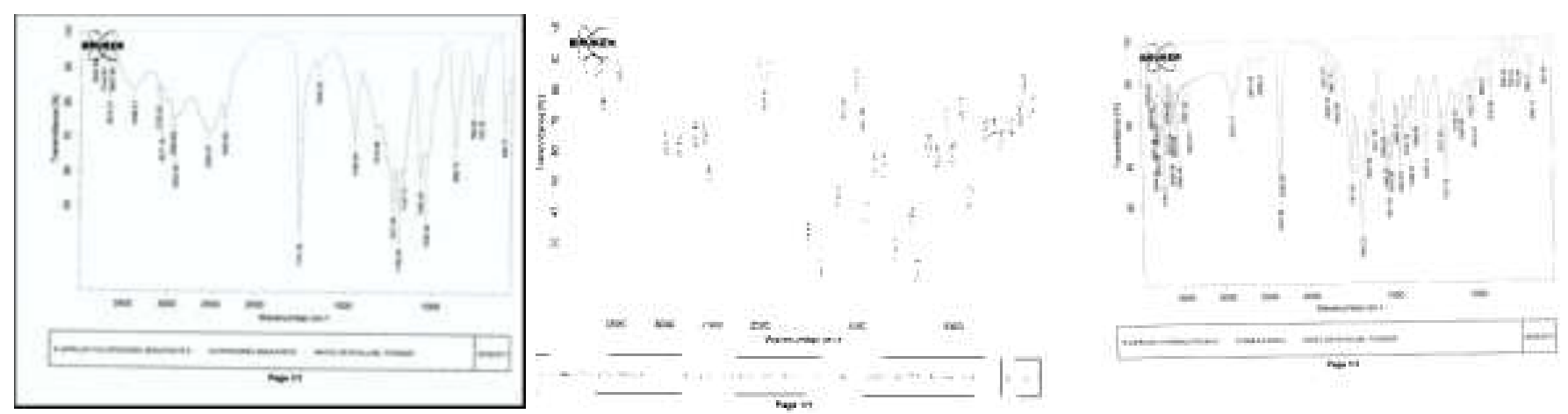

Figure 1: Qualitative analysis of functional groups in the prepared formulation.

Clopidrogel bisulphate acetyl salicylic acid formulation F6 (Optimized Formulation) (Table 8)

\begin{tabular}{|l|l|}
\hline Drug & Finger print region \\
\hline Clopidogrel bisulphate & $3300 \mathrm{~cm}^{-1}-841 \mathrm{~cm}^{-1}$ \\
\hline Aspirin & $3300 \mathrm{~cm}^{-1}-1000 \mathrm{~cm}^{-1}$ \\
\hline
\end{tabular}

Table 8: Finger print region range

The following are the IR values for the prominent peaks in the finger print region

For Clopidogrel bisulphate (Table 9)

\begin{tabular}{|l|c|}
\hline Functional groups & \multicolumn{1}{|c|}{ Wave number $(\mathbf{c m}-\mathbf{n})$} \\
\hline C-O stretching & $1155 \mathrm{~cm}^{-1}$ \\
& $1187 \mathrm{~cm}^{-1}$ \\
\hline $\mathrm{C}=\mathrm{O}$ Stretching & $1752 \mathrm{~cm}^{-1}$ \\
\hline $\mathrm{N}^{+}-\mathrm{H}$ Stretching & $2500-2550 \mathrm{~cm}^{-1}$ \\
\hline C-H Stretching & $3121 \mathrm{~cm}^{-1}$ \\
\hline O-H Stretching & $3300 \mathrm{~cm}^{-1}$ \\
\hline
\end{tabular}

Table 9: IR values for the prominent peaks in the finger print region.

\section{For Aspirin (Table 10)}

\begin{tabular}{|l|r|}
\hline Functional groups & Wave number $\left(\mathbf{c m} \mathbf{m}^{-1}\right)$ \\
\hline $\mathrm{C}=\mathrm{C}$ (Aromatic) & $1600-1400 \mathrm{~cm}^{-1}$ \\
\hline $\mathrm{C}=\mathrm{O}$ (ester) & $1750-1730 \mathrm{~cm}^{-1}$ \\
\hline $\mathrm{C}=\mathrm{O}$ (carboxylic acid) & $1725-1700 \mathrm{~cm}^{-1}$ \\
\hline $\mathrm{C}-\mathrm{O}$ (ester/carboxylic acid) & $1300-1000 \mathrm{~cm}^{-1}$ \\
\hline $\mathrm{O}-\mathrm{H}$ (carboxylic acids) & $3300-2500 \mathrm{~cm}^{-1}$ \\
\hline
\end{tabular}

Therefore, based on the above mentioned wave numbers $\left(\mathrm{cm}^{-1}\right)$ different functional groups are characterized in the finger print region of IR spectrum of the pure API (i.e. Clopidogrel bisulphate and Aspirin) and are inturn compared with the IR spectrum of the formulation blend (API+excipients) to check whether there is a shift in the prominent peaks of the API in the presence of excipients. The above graph suggests that there are no significant changes in the prominent peaks of both the drugs i.e Clopidogrel bisulphate as well as Aspirin in the presence of excipients. Therefore, it may be concluded that the given list of excipients are very much compatible with both the drugs. Standard absorbances are measured in $0.1 \mathrm{Hcl}$ (Table 11, Figures 2 and 3 ).

\begin{tabular}{|l|c|c|c|}
\hline S.NO & Concentration $\mathbf{( \mu g} / \mathbf{m l})$ & Absorbance for CPS & 0.006 \\
\hline 1 & 2 & 0.100 & 0.013 \\
\hline 2 & 4 & 0.175 & 0.022 \\
\hline 3 & 8 & 0.298 & 0.035 \\
\hline
\end{tabular}




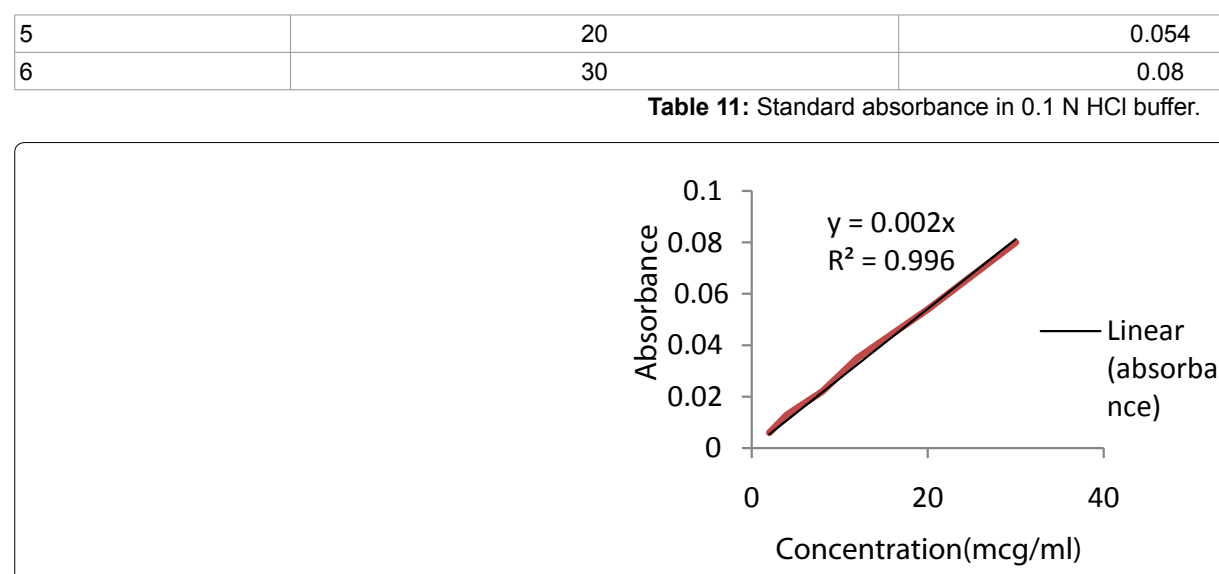

Figure 2: Standard curve for Clopidogrel bisulphate.

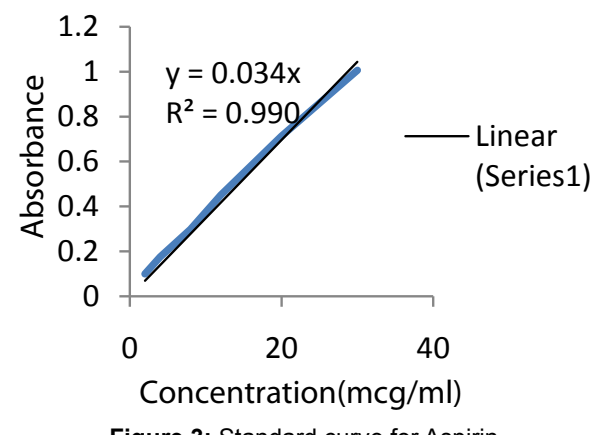

\begin{tabular}{|c|c|}
\hline Drug & Regression coefficient $\left(\mathbf{R}^{2}\right)$ \\
\hline CPS & 0.996 \\
\hline ASA & 0.990 \\
\hline
\end{tabular}

Table 12: Regression coefficient.

The regression values generated shows that estimation of CPS and ASA by UV spectroscopy in $0.1 \mathrm{~N}$ HCl dissolution buffer has good reproducibility (Table 12).

Analysis of reference product Analysis of the reference Product was carried out and results recorded in the following table (Table 13).

\begin{tabular}{|c|c|c|}
\hline SNO & Parameter & Description \\
\hline 1 & Shape & Flat, round \\
\hline 2 & Color & Light pink-white \\
\hline 3 & Thickness $(\mathrm{mm})$ & 4.0 \\
\hline 4 & Diameter $(\mathrm{mm})$ & 11.0 \\
\hline 5 & Hardness $\left(\mathrm{kg} / \mathrm{cm}^{2}\right)$ & $4.5-5.0$ \\
\hline
\end{tabular}

Table 13: Analysis of reference product.

\section{In vitro Dissolution Study of Reference Product}

As the formulation "Clopidogrel bisulphate and Aspirin immediate-release bilayer tablets" is not official in any pharmacopoeia, analytical method development was modelled on the "Quantitative Analysis of Clopidogrel bisulphate And Aspirin by Second Derivative Spectrophotometric Method in Pharmaceutical Preparation" [11]. Since Clopidogrel bisulphate is a Class-II drug, its solubility is very low (i.e. $0.0099 \mathrm{mg} / \mathrm{ml}$ ). Therefore, "A Solid dispersion technique- Fusion method" is employed to enhance its solubility. The process for the formulation of Clopidogrel bisulphate immediate release layer was developed in a systematic way. Trials were taken by selection of suitable ratio of solid dispersing agent PEG-4000 in which the drug showed greater solubility. The results are discussed in the following table (Table 14).

\begin{tabular}{|c|c|c|c|c|c|}
\hline Ingredients & $\begin{array}{l}\text { Qty in mg per tab(for } \\
\text { pure drug) }\end{array}$ & $\begin{array}{l}\text { Qty in mg per } \\
\operatorname{tab}(1: 0.25)\end{array}$ & Qty in mg per tab(1:0.5) & Qty in mg per tab(1:1) & $\begin{array}{l}\text { Qty in mg per } \\
\text { tab(1:1.25) }\end{array}$ \\
\hline Clopidogrel bisulphate & 98.0 & 98.0 & 98.0 & 98.0 & 98.0 \\
\hline PEG-4000 & - & 24.5 & 49.0 & 98.0 & 122.5 \\
\hline
\end{tabular}


Citation: Abdul Althaf S, Sailaja PB, Ashwin Kumar M (2012) Formulation, Evaluation and Mathematical Modelling of Clopidogrel Bisulphate \& Aspirin Immediate Release Bilayer Tablets. Pharmaceut Anal Acta 3: 194. doi:10.4172/2153-2435.1000194

Page 7 of 11

\begin{tabular}{|l|c|c|c|c|}
\hline Absorbance & 0.006 & 0.013 & 0.022 & 0.035 \\
\hline Concentration or Solubility $(\mathrm{mcg} / \mathrm{ml})$ & 3 & 6.5 & 11 & 27 \\
\hline
\end{tabular}

Based on the above data, the solubility of Clopidogrel bisulphate was found to be highest in 1:1 ratio (drug:carrier). Solid dispersion formulated in 1:1 ratio showed a 9 fold increase in solubility when compared with pure drug. Therefore, the 1:1 ratio of solid dispersion was finally selected for the formulation of Clopidogrel bisulphate immediate release layer.

\section{Selection of formulation process}

Selection of process of formulation for Clopidogrel bisulphate is "Direct compression" due to the hygroscopic nature of PEG-4000 solid dispersion and "Dry granulation" for Aspirin layer to achieve effective binding with Clopidogrel bisulphate layer.

\section{Comparative composition of all formulations}

Comparative Composition profile of all the designed formulations for both the layers are shown in the tables 1 and 2.

\section{Parameters for evaluation of designed formulation pre-compression parameters}

(For evaluation of lubricated blend ready for compression) Pre-compression parameters of all the formulations are shown in the following table (Table 15).

\section{Parameter}

Bulk density $(\mathrm{g} / \mathrm{ml})$

Tap density $(\mathrm{g} / \mathrm{ml})$

Compressibility Index (\%)

Hausner's ratio

Angle of repose

Loss on drying (\%)

\section{Clopidogrel bisulphate}

0.375

0.450

16.667

1.20

$27.847^{\circ}$

0.3

\begin{tabular}{|c|}
\hline Aspirin \\
0.658 \\
0.781 \\
15.789 \\
1.188 \\
\hline $23.07^{\circ}$ \\
0.4 \\
\hline
\end{tabular}

Table 15: Pre-compression parameters of all the formulations.

\section{Post compression parameters (evaluation of compressed tablets)}

Post compression parameters of all formulation are shown in the following tables (Tables 16-21).

\begin{tabular}{|c|c|}
\hline Formulation & Average hardness $\left(\mathbf{k g} / \mathbf{c m}^{\mathbf{2}}\right)$ \\
\hline $\mathrm{F}_{1}$ & 4.5 \\
\hline $\mathrm{F}_{2}$ & 3.5 \\
\hline $\mathrm{F}_{3}$ & 4.0 \\
\hline $\mathrm{F}_{4}$ & 4.0 \\
\hline $\mathrm{F}_{5}$ & 3.5 \\
\hline $\mathrm{F}_{6}$ & 3.0 \\
\hline $\mathrm{F}_{7}$ & 3.5 \\
\hline
\end{tabular}

Table 16: Average hardness of various bilayer formulations of Clopidogrel bisulphate and Aspirin.

\begin{tabular}{|c|c|}
\hline Formulation & Thickness (mm) \\
\hline$F_{1}$ & 4.22 \\
\hline$F_{2}$ & 4.22 \\
\hline$F_{3}$ & 4.24 \\
\hline$F_{4}$ & 4.24 \\
\hline$F_{5}$ & 4.20 \\
\hline$F_{6}$ & 4.22 \\
\hline$F_{7}$ & 4.23 \\
\hline
\end{tabular}

Table 17: Average thickness of various bilayer formulations of Clopidogrel bisulphate and Aspirin.

\begin{tabular}{|c|c|c|}
\hline Formulation & \% Wt variation & Result \\
\hline$F_{1}$ & 1.2 & Passes \\
\hline$F_{2}$ & 0.9 & Passes \\
\hline$F_{3}$ & 1.5 & Passes \\
\hline$F_{4}$ & 0.5 & Passes \\
\hline$F_{5}$ & 0.8 & Passes \\
\hline$F_{6}$ & 0.5 & Passes \\
\hline$F_{7}$ & 0.8 & Passes \\
\hline
\end{tabular}

Table 18: Weight variation test of various bilayer formulations of Clopidogrel bisulphate and Aspirin. 
Citation: Abdul Althaf S, Sailaja PB, Ashwin Kumar M (2012) Formulation, Evaluation and Mathematical Modelling of Clopidogrel Bisulphate \& Aspirin Immediate Release Bilayer Tablets. Pharmaceut Anal Acta 3: 194. doi:10.4172/2153-2435.1000194

Page 8 of 11

\begin{tabular}{|c|c|}
\hline$F_{1}$ & 16 \\
\hline$F_{2}$ & 14 \\
\hline$F_{3}$ & 12 \\
\hline$F_{4}$ & 15 \\
\hline$F_{5}$ & 8 \\
\hline$F_{6}$ & 7 \\
\hline$F_{7}$ & 10 \\
\hline Table 19: Disintegration time of various bilayer tablets of Clopidogrel bisulphate and Aspirin. \\
\hline
\end{tabular}

\begin{tabular}{|c|c|c|}
\hline \multicolumn{1}{|c|}{ Formulation } & \multicolumn{2}{|c}{ Percentage of drug content (\%) } \\
\cline { 2 - 3 } & Clopidogrel bisulphate & 99.2 \\
\hline Reference & 95.59 & 97.43 \\
\hline$F_{1}$ & 96.42 & 99.4 \\
\hline$F_{2}$ & 98.20 & 96.34 \\
\hline$F_{3}$ & 97.59 & 97.72 \\
\hline$F_{4}$ & 95.20 & 97.83 \\
\hline$F_{5}$ & 94.65 & 98.45 \\
\hline$F_{6}$ & 97.21 & 97.68 \\
\hline$F_{7}$ & 97.90 & \\
\hline
\end{tabular}

Table 20: Percentage of drug content of various formulations of bilayer tablets of Clopidogrel bisulphate and Aspirin.

\begin{tabular}{|c|c|c|}
\hline Formulation & Percentage of Weight loss (\%) & Result \\
\hline$F_{1}$ & 1.2 & Fails \\
\hline$F_{2}$ & 0.7 & Passes \\
\hline$F_{3}$ & 0.8 & Passes \\
\hline$F_{4}$ & 0.8 & Passes \\
\hline$F_{5}$ & 0.9 & Passes \\
\hline$F_{6}$ & 0.5 & Passes \\
\hline$F_{7}$ & 0.8 & Passes \\
\hline
\end{tabular}

Table 21: Friability data of various formulations of bilayer tablets of Clopidogrel bisulphate and Aspirin.

\section{In vitro Drug Release Profile of all Bilayer Formulations}

Six tablets of each formulation were randomly chosen and weighed. One tablet was transferred into each dissolution vessel containing $900 \mathrm{ml}$ $0.1 \mathrm{~N} \mathrm{HCl}$ buffer. After completion of one hour, dissolution was halted and samples were collected. The amount of drug released was determined by analyzing the aliquots removed at regular intervals by UV spectrophotometric method.

\section{In vitro drug release profile for immediate release Clopidogrel bisulphate layer}

Based on the above results, the formulation $\mathrm{F}_{6}\left(\mathrm{C}_{6}+\mathrm{A}_{6}\right)$ was concluded as the best-fit optimized formula (Figure 4).

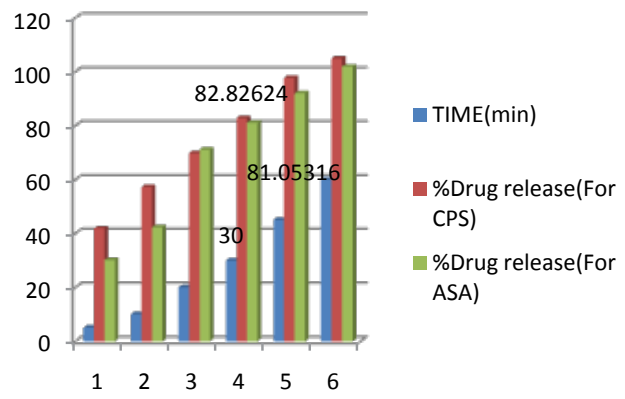

Figure 4: Best fit optimized formulation $\left(\mathrm{F}_{6}\right)$ dissolution graph.

\section{Study of Dissimilarity $(f 1)$ and Similarity $(f 2)$ Factors}

A statistical comparison of dissolution data was carried out using dissimilarity $(f 1)$ and similarity $(f 2)$ factors for all formulations i.e. $\mathrm{F}_{1}$ to $\mathrm{F}_{7}$ but formulations 5, 6 were found to be in limits. The comparison of in vitro dissolution profiles of products F-5 and F- 6 with reference product are shown in the following tables (Tables 22 and 23). 


\begin{tabular}{|l|c|c|}
\hline $\mathrm{F}_{5}$ & -5.74826561 \\
\hline $\mathrm{F}_{6}$ & 3.468780971 & 99.99427968 \\
\hline & \multicolumn{1}{|c|}{ Table 22: $f_{1}$ and $f_{2}$ studies results for Clopidogrel Bisulphate. } \\
\hline $\mathrm{F}_{5}$ & 8.597172853 & 99.99853436 \\
\hline $\mathrm{F}_{6}$ & 14.61519385 & 98.5779597 \\
\hline
\end{tabular}

Table 23: $f_{1}$ and $f_{2}$ studies results for Aspirin.

It was observed that in the formulation $\mathrm{F}_{6}$ dissimilarity $(f 1)$ factor was lowest (much below 15 ) while the similarity $(f 2)$ factor was highest (much above 50) for both the layers indicating that the developed bilayer tablet formulation has in vitro dissolution profile identical to the reference product, and that the developed prototype $\mathrm{F}_{6}$ possess greater possibility of passing the in vivo bioequivalence test.

\section{Mathematical Modeling of In vitro Dissolution Data}

Release rates obtained from the optimized formulation $\mathrm{F}_{6}$ was subjected to kinetic treatment to understand the drug release behaviour. The data were grouped according to five modes of data treatment as follows:

- $\quad$ Cumulative percent drug released $v s$. time (zero order release kinetics)

- $\quad$ Log cumulative percent drug retained $v s$. time (first order release kinetics)

- $\quad$ Cumulative percent drug released $v s$. square root of time (Higuchi model of drug release kinetics)

- $\quad$ Cube root of percent drug remaining vs. time (Hixson - Crowell cube root law)

- $\quad$ Log cumulative percent drug released $v s$. Log time (Korsmeyer-peppas model of drug release kinetics).

\section{Stability Studies}

The effect of temperature and humidity on in vitro drug release, and Drug content of optimized bilayer tablet formulation $\mathrm{F}_{6}$ was performed at three stability storage conditions, as per ICH guidelines (for 30 days).

- $40 \pm 2^{\circ} \mathrm{C} / 75 \pm 5 \% \mathrm{RH}$ (minimum study period atleast 1 month)

- $\quad 30 \pm 2^{\circ} \mathrm{C} / 65 \pm 5 \% \mathrm{RH}$ (minimum study period atleast 2 months)

- $\quad 25 \pm 2^{\circ} \mathrm{C} / 60 \pm 5 \% \mathrm{RH}$ (minimum study period atleast 2 months)

The tablets were analyzed for percent drug release and uniformity of drug content at the interval of 30 days (Tables 24-26).

\begin{tabular}{|c|c|c|}
\hline SNO & Time(min) & \% Drug Release \\
\hline 1 & 5 & 33.02133 \\
\hline 2 & 10 & 57.11798 \\
\hline 3 & 20 & 89.69307 \\
\hline 4 & 30 & 93.70918 \\
\hline 6 & 45 & 97.72529 \\
\hline
\end{tabular}

\begin{tabular}{|c|c|c|}
\hline SNO & Time(min) & $\%$ Drug Release \\
\hline 1 & 5 & 29.77215 \\
\hline 2 & 10 & 41.64051 \\
\hline 3 & 20 & 61.97468 \\
\hline 4 & 30 & 81.9038 \\
\hline 5 & 45 & 95.3519 \\
\hline 6 & 60 & 101.7924 \\
\hline
\end{tabular}

\begin{tabular}{|l|l|l|l|l|l|l|}
\hline Formulation & Percentage of drug content (\%) & Aspirin \\
\hline Formulation-6 & Clopidogrel bisulphate & 97.2 \\
\hline & $96.59 \quad$ Table 26: Percentage of drug content of formulation $\left(F_{6}\right)$. & \\
\hline
\end{tabular}

The results obtained showed no significant variation ( 1 to $3 \%$ ) in the drug release and assay. From the above results it was concluded that the $\mathrm{F}_{6}$ was stable at $40 \pm 2^{\circ} \mathrm{C}$ and $75 \pm 5 \% \mathrm{RH}$ for 30 days.

\section{Discussion}

Since Clopidogrel bisulphate is a Class-II drug, its solubility is very low (i.e., $0.0099 \mathrm{mg} / \mathrm{ml}$ ) and has very low bioavailability. Therefore, "A 
Solid dispersion technique- Fusion method" was employed to enhance its solubility and inturn improve its bioavailability. The process for the formulation of Clopidogrel bisulphate immediate release layer was developed in a systematic way. Trials were taken by selection of suitable ratio of solid dispersing agent (PEG-4000) as a carrier. Based on the solubility data, the solubility of Clopidogrel bisulphate was found to be highest in 1:1 ratio (drug:carrier) of solid dispersion. It had showed a 9 fold increase in solubility when compared with pure drug. Therefore, 1:1 ratio of solid dispersion was finally selected for the formulation of Clopidogrel bisulphate immediate release layer. The trial formulation $\mathrm{F}_{1}$ was taken to select process preparation of immediate release bilayer tablet; formulations $\mathrm{F}_{2}, \mathrm{~F}_{3}, \mathrm{~F}_{4}$ were taken to study the effect of superdisintegrants like Sodium starch glycollate, Crospovidone, Croscarmellose sodium respectively. The comparison of percentage release rates of formulations $\mathrm{F}_{2}, \mathrm{~F}_{3}$, $\mathrm{F}_{4}$ revealed that immediate- release profile was not achieved with combinations of $4 \%$ of Sodium starch glycollate, Crospovidone, Croscarmellose sodium respectively. Therefore, a further increase in the concentration of superdisintegrants was achieved. Three different formulations $\left(\mathrm{F}_{5}, \mathrm{~F}_{6}, \mathrm{~F}_{7}\right)$ comprising a $6 \%$ of Sodium starch glycollate, Crospovidone, Croscarmellose sodium respectively were compared. Amongst these, formulation $\mathrm{F}_{6}$ comprising Crospovidone showed the closest resemblance to reference product in terms of dissolution profile fact, further validated by the high similarity factor and low dissimilarity factor.

Recent advances in novel drug delivery systems aim to enhance safety and efficacy of drug molecules by formulating a convenient dosage form for administration and to achieve better patient compliance. Once daily dosing of drugs through design of immediate release oral bilayer tablet formulation is the most preferred approach in improving patient convenience, drug therapy and safety.

In the present investigation, an attempt was made to formulate an immediate - release oral bilayer tablet formulation of Clopidogrel bisulphate and Aspirin through application / incorporation of Solid dispersion technique to Clopidogrel bisulphate for the enhancement of its solubility. The study was aimed at developing a tablet formulation in vitro dissolution profile identical to reference. Evaluation of the optimized immediate-release bilayer tablet formulation revealed that the product $\mathrm{F}_{6}$ was superior to other prototypes under development with regards to physical attributes of tablet such as percentage weight variation, friability, assay and all others were found to be within pharmacopoeial limits. In vitro drug dissolution demonstrated immediate drug release within 30 minutes in a manner quite identical to Reference Product. Least dissimilarity $(f)$ factor value and highest similarity $\left(f_{2}\right)$ factor value indicating that the developed product has the capacity to pass in vivo bioequivalence test ( $\mathrm{F}_{6}$, for CLP layer $f_{1}$ is $3.368 \& f_{2}$ is 99.99 and for ASP layer $f_{1}$ is $3.368 \& f_{2}$ is 99.99). Drug release kinetics follow the Korsmeyer peppas drug release model, which shows diffusion controlled drug release, an attribute highly desirable for any immediate - release formulation. Good storage stability as assessed by short term stability studies as per ICH guidelines. In conclusion, a stable immediate-release oral bilayer tablet formulation of Clopidogrel bisulphate and Aspirin was successfully developed that has in vitro drug release characteristics identical to the reference product. Moreover, the developed product is less complex with regards to formulation components and processing aspects.

This formula and process can be easily scaled up and can be easily employed in large scale production because the process is simple, cheap and precise and also yield reproducible good tablets. As an extension of this work, bioavailability and pharmacokinetic studies on this drug delivery system can be done in future.

\section{References}

1. USP XXXI VOL-I, 2008, 231-232.

2. USP XXXI VOL-I, 2008, 640-641.

3. USP XXXI VOL-I, 2008, 639-640.

4. Madhuri DG, Sakarkar DM (2010) and aspirin by second derivative spectrophotometric method in pharmaceutical preparation. International Journal of ChemTech Research 2: 1886-1891.

5. Andrei AB, Aboul-Enein HY, Serban Fleschin (2006) FT-IR Spectrophotometric analysis of acetylsalicylic acid and its pharmaceutical formulations. Canadian Journal of Analytical Sciences and Spectroscopy, 253-259.

6. Ramesh, Satish kumar D, Guruvaiah, Harini A (2010) Formulation and Evaluation of the Bi-layered sustained Release Matrix Tablets of Metformin HCl Sr and Pioglitazone. American and Eurasian Journal of Scientific Research 5: 176-182.

7. Lachmann L, Lachmann HA, Kanico JL. The Theory and Practice of Industrial Pharmacy. (3rdedn), 296-303.

8. USP-XXXI, NF-26, 2: 1821,1450

9. Varma VS, Kaushal AM, Garg A, Garg S (2004) Factors affecting mechanism and kinetics of drug release from matrix- based oral controlled drug delivery system. Am J Drug Deliv 2: 43-57.

10. Natalie MC Clure (1997) Stability Studies in Overview of ICH Guidelines for Drug products, Matric Pharmaceutical Inc.

11. Goldberg A, Gibaldi M, Kanig JL (1966) Increasing dissolution rates and gastrointestinal absorption of drugs via solid solutions and eutectic mixtures III - experimental evaluation of griseofulvin- succinic acid solid solution. J Pharm Sci 55: 487-492.

12. Vasconcelos T, Costa P (2007) Development of a rapid dissolving ibuprofen solid dispersion. In: PSWC - Pharmaceutical Sciences World Conference, DD-W- 103.

13. Vasconcelos T, Costa P (2007) Development of a rapid dissolving ibuprofen solid dispersion. In: PSWC - Pharmaceutical Sciences World Conference, DD-W- 103.

14. Pokharkar VB, Leenata PM, Mahesh NP, Anshuman AA, Kakasaheb RM, et al. (2006) Development, characterization and stabilization of amorphous form of a low Tg drug. Powder Technol 167: 20-25.

15. Taylor LS, Zografi G (1997) Spectroscopic characterization of interactions between PVP and indomethacin in amorphous molecular dispersions. Pharm Res 14: 16911698.

16. Vippagunta SR, Wang Z, Hornung S, Krill SL (2006) Factors affecting the formation of eutectic solid dispersions and their dissolution behavior. J Pharm Sci 96: 294-304.

17. Chiou WL, Riegelman S (1971) Pharmaceutical applications of solid dispersion systems. J Pharm Sci 60: 1281-1302. 
Citation: Abdul Althaf S, Sailaja PB, Ashwin Kumar M (2012) Formulation, Evaluation and Mathematical Modelling of Clopidogrel Bisulphate \& Aspirin Immediate Release Bilayer Tablets. Pharmaceut Anal Acta 3: 194. doi:10.4172/2153-2435.1000194

18. Sekiguchi K, Obi N (1961) Studies on Absorption of Eutectic Mixture. I. A comparison of the behaviour of eutectic mixture of sulfathiazole and that of ordinary sulfathiazole in man. Chem Pharm Bull 9: 866-872.

19. Damian F, Blaton N, Kinget R, Van den Mooter G (2002) Physical stability of solid dispersions of the antiviral agent UC-781 with PEG 6000 , Gelucire 44/14 and PVP K30. Int J Pharm 244: 87-98.

20. Vippagunta SR, Maul A, Tallavajhala S, Grant DJW (2002) Solid-state characterization of nifedipine solid dispersions. Int J Pharm 236: 111 -123.

21. Breitenbach J (2002) Melt extrusion: from process to drug delivery technology. Eur J Pharm Biopharm 54: $107-117$.

22. Langer M, Höltje M, Urbanetz NA, Brandt B, Höltje HD, et al. (2003) Investigations on the predictability of the formation of glassy solid solutions of drugs in sugar alcohols. Int J Pharm 252: 167-179.

23. Hernandez-Trejo N, Hinrichs WLJ, Visser, MR, Müller RH, Kayser O, et al. (2005) Enhancement of the in vitro dissolution rate of the lipophilic drug buparvaquone by incorporation into solid dispersions. In: PharmSci Fair. Nice, France.

24. Betageri GV, Makarla KR (1995) Enhancement of dissolution of glyburide by solid dispersion and lyophilization techniques. Int J Pharm 126: 155-160.

25. Kushida I, Ichikawa M, Asakawa N (2002) Improvement of dissolution and oral absorption of ER- 34122, a poorly water-soluble dual 5-lipoxygenase/cyclooxygenase inhibitor with anti-inflammatory activity by preparing solid dispersion. J Pharm Sci 91: 258-266.

26. Paradkar A, Ambike AA, Jadhav BK, Mahadik KR (2004) Characterization of curcumin-PVP solid dispersion obtained by spray drying. Int J Pharm 271: $281-286$.

27. Weuts I, Kempen D, Verreck G, Decorte A, Heymans K (2005) Study of the physicochemical properties and stability of solid dispersions of loperamide and PEG6000 prepared by spray drying. Eur J Pharm Biopharm 59: 119-126. 